\title{
Nanostructured Composites Based on Carbon Nanotubes and Epoxy Resin for Use as Radar Absorbing Materials
}

\author{
Valdirene Aparecida Silva ${ }^{\mathrm{a}}$ Luiza de Castro Folgueras ${ }^{\mathrm{b}}$, Geraldo Maurício Cândido ${ }^{\mathrm{b}}$, \\ Adriano Luiz de Paula ${ }^{\mathrm{b}}$ Mirabel Cerqueira Rezende ${ }^{c *}$, Michelle Leali Costa ${ }^{\mathrm{b}, \mathrm{d}}$ \\ ${ }^{a}$ Aeronautical Institute of Technology - ITA, São José dos Campos, SP, Brazil \\ ${ }^{\mathrm{b}}$ Materials Division, Institute of Aeronautics and Space, São José dos Campos, SP, Brazil \\ ${ }^{c}$ Materials Division, Institute of Aeronautics and Space and Aeronautical Institute of Technology - ITA, \\ São José dos Campos, SP, Brazil \\ ${ }^{\mathrm{d}}$ Department of Materials and Technology - DMT, Universidade Estadual Paulista - UNESP, \\ Guaratinguetá, SP, Brazil
}

Received: March 20, 2013; Revised: May 20, 2013

\begin{abstract}
Nanostructured polymer composites have opened up new perspectives for multifunctional materials. In particular, carbon nanotubes (CNTs) present potential applications in order to improve mechanical and electrical performance in composites with aerospace application. The combination of epoxy resin with multiwalled carbon nanotubes results in a new functional material with enhanced electromagnetic properties. The objective of this work was the processing of radar absorbing materials based on formulations containing different quantities of carbon nanotubes in an epoxy resin matrix. To reach this objective the adequate concentration of CNTs in the resin matrix was determined. The processed structures were characterized by scanning electron microscopy, rheology, thermal and reflectivity in the frequency range of 8.2 to $12.4 \mathrm{GHz}$ analyses. The microwave attenuation was up to $99.7 \%$, using only $0.5 \%(\mathrm{w} / \mathrm{w})$ of CNT, showing that these materials present advantages in performance associated with low additive concentrations.
\end{abstract}

Keywords: nanostructured composites, radar absorbing materials, carbon nanotubes, epoxy, thermal analyses

\section{Introduction}

The technology that involves the electromagnetic wave absorbing materials is important for a wide variety of applications, ranging from minimizing radar signature of a target, protection of human eyes, optical sensors from intense laser pulses, protective shielding of computers and consumer electronics. With the emergence of new target detection modes, especially multifrequency detection, composites with multiwalled carbon nanotubes embedded into a polymer matrix have been studied for applications in the microwave frequency range, such as antireflections, electromagnetic interference shielding and microwave absorbers $^{1,2}$.

Radar Absorbing Materials (RAM) provide energy losses of electromagnetic radiation. In certain frequency bands, these materials attenuate the incident electromagnetic wave radiation and dissipate the energy absorbed in the form of heat through internal mechanisms, magnetic and/or dielectrics. These loss mechanisms can be physical, chemical or simultaneously both ${ }^{3,4}$. Increased electromagnetic pollution due to the presence of microwaves and the use of stealth technology in defense systems and military platforms have been the major attractions for studies in this area, with investments in research that already cover the frequency

*e-mail: mirabelmcr@iae.cta.br range of 1-40 $\mathrm{GHz}^{5}$. Some recent studies have described radar absorbing structures applied in the frequency range of 10 to $100 \mathrm{GHz}^{6,7}$.

RAM application can be done in both civilian and military sectors. Considering applications of these materials in military area it can say that the energy scattered from a target (eco-radar), that would be used for its detection by radar, is attenuated and the object coated with RAM becomes stealth or, as reported in the literature, "invisible" to radar. In civilian applications, the RAM use brings benefits in different areas, such as in telecommunication area coating cell phones and radio transmitting antennas; in medical sector coating, for example, electronic pacemakers and equipment; in anechoic chambers used for research and industrial purposes; in home appliances in general, in electromagnetic shielding and control of interference, among other applications ${ }^{8-10}$.

Usually, microwave absorbing coatings are composite materials that may present itself in various forms such as plates of elastomeric polymers based on polyisoprene and polychloroprene; flexible blankets of different types of rubbers and paints based on epoxy, phenolic and polyurethane resins $s^{3,11,12}$. An important characteristic of these composites is the possibility to adjust their electrical 
and magnetic properties to optimize the attenuation of incident microwaves. This can occur at specific frequencies (resonant type) or in a broad spectrum of frequencies (broadband type $)^{7}$. Relevant characteristics are continuously investigated in the area of RAM: durability, low density, low cost, performance on a wide range of frequencies and also the ease of application ${ }^{7,8,13,14}$.

Epoxy resins are the most important thermosets, widely used as adhesives, coatings, and composite materials ${ }^{15-18}$. In recent years, the use of carbon nanotubes (CNTs) in epoxy resin/carbon nanotube composites has attracted a great deal of attention ${ }^{19-26}$. CNTs have a unique atomic structure, very high aspect ratio, and extraordinary electrical, magnetic and mechanical properties (strength and flexibility), making them ideal reinforcing in nanostructured composites or nanocomposites.

More and more studies involving the dispersion of nanotubes in polymer matrix have been reported aiming to improve electrical and mechanical properties of the nanostructured composites ${ }^{23,27-31}$. Aggregations of nanotubes due to van der Waals interactions and shear forces during mixing have been reported to cause a drop in electrical conductivity ${ }^{32-34}$. Considering high aspect ratio and good dispersion, nanotubes can reach conductivity thresholds at lower loading levels and can create networks that facilitate the electron transport. In addition to the aspect ratio and the dispersion, several studies have shown that various processing parameters affect the properties of the resulting nanostructured composites $27,30,35-40$.

The processes of covalent and noncovalent functionalization have been suggested as one of the options for better dispersion of nanotubes ${ }^{27,41-43}$. The chemical modification of the nanotube surface through covalent functionalization results in reduction of the aspect ratio with the formation of $\mathrm{sp}^{3}$ carbons on nanotube surface, which decreases the electrical conductivity of nanotubes ${ }^{27,44-47}$. Therefore, as-received nanotubes were used in the present work without any functionalization, once this study is focused on the electromagnetic properties.

A tube configuration of CNTs enables them to have a so-called electronic conjugate $\pi$ structure which is responsible for its unique electronic transport behaviors. Theoretical calculations show that CNTs act to like insulators, semiconductors or metals depending on their radii and chiralities. Composites with multiwalled carbon nanotubes (MWNTs) embedded into a polymer host have been use to microwave applications, such as antireflection, electromagnetic interference shielding (EMI) or microwave absorber $^{1,47-54}$

Thus, the objective of this work was to process nanostructured composite materials based on formulations containing different quantities of multiwalled carbon nanotubes in an epoxy resin matrix, aiming to determine the adequate quantity of CNT for processing X-band microwave absorbing nanostructured composite.

\section{Experimental}

\subsection{Nanostructured composites production}

For the absorbing nanostructured composites processing, carbon nanotubes were dispersed in an epoxy resin matrix.
Carbon nanotubes were acquired from ILJIN NANOTECH Co. Ltd., a Korea enterprise (type CM-95/MWNT). According to the manufacturer this MWNT has size of $0.01-0.015 \mu \mathrm{m}$ of diameter and 10-20 $\mu \mathrm{m}$ of length. The used polymer matrix was the Epikote ${ }^{\mathrm{TM}}$ Resin MGS ${ }^{\circledR}$ L135 epoxy resin by Hexion, which is transparent in the frequency range evaluated ( 8.2 to $12.4 \mathrm{GHz}$ ). To obtain nanostructured composites were used formulations with $0.1,0.5$ and $1.0 \%$ in weight $(\mathrm{w} / \mathrm{w})$ of CNT dispersed in the epoxy resin. To achieve more homogeneous dispersion of the nanotubes (powder) in the polymer matrix was used an ultrasonic homogenizer tip (sonicator) for 10 min utilizing $25 \%$ of its maximum amplitude $(750 \mathrm{~W}, 20 \mathrm{kHz})$. This was used for the mixtures added with 0.1 to $1.0 \%$ (w/w) of CNTs. The cure of polymer matrix was obtained using a hardener (type Hardener 137 by Hexion ${ }^{\mathrm{TM}}$ ) under room temperature $\left(25 \pm 2{ }^{\circ} \mathrm{C}\right)$ and atmospheric pressure for $8 \mathrm{~h}$. The specimens were prepared according to the requirements of the characterization techniques used, as follow.

\subsection{Nanostructured composites characterization}

The cured nanostructured composites were characterized by scanning electron microsocope LEO, model $435 \mathrm{VPi}$, aiming the investigation of the surface and the dispersion of CNTs in the processed materials. Samples submitted for analysis by scanning electron microscopy (SEM) were fixed on aluminum holders and coated with a gold thin film prepared by vacuum evaporation, to ensure the conductivity of the surface.

Rheological analyses were performed to measure the initial viscosity of CTNs/epoxy composites. For this, it was used an SR5 stress-controlled rheometer (Rheometrics Scientific Inc.) equipped with heated plates. These analyses were performed at room temperature $\left(25 \pm 2{ }^{\circ} \mathrm{C}\right)$; frequency of $1 \mathrm{rad} / \mathrm{s}$ and stress of $200 \mathrm{~Pa}$.

Dynamic mechanical analyses (DMA) were carried out to measure the storage and the loss modulus of cured samples. A TA Instruments 2980 DMA, coupled to a single cantilever module, at constant frequency of $1 \mathrm{~Hz}$ and $15 \mu \mathrm{m}$ of amplitude was used. Specimens of $20 \mathrm{~mm} \times 13 \mathrm{~mm}$ and thickness of $2.0 \mathrm{~mm}$ were machined so as to fit in the sample holders. The studies were conducted starting at room temperature $\left(25 \pm 2{ }^{\circ} \mathrm{C}\right)$ up to $300{ }^{\circ} \mathrm{C}$ using the heating rate of $2{ }^{\circ} \mathrm{C} \cdot \mathrm{min}^{-1}$. The ratio of the storage and the loss modulus, given as tan delta $(\delta)$, provided the glass transition temperatures.

Thermogravimetric analyses (TGA) of cured samples were evaluated with PerkinElmer 7HT TGA, which was fitted to a nitrogen purge gas from room temperature $\left(25 \pm 2{ }^{\circ} \mathrm{C}\right)$ up to $800{ }^{\circ} \mathrm{C}$, at heating rate of $10^{\circ} \mathrm{C} \cdot \mathrm{min}^{-1}$.

\subsection{Electromagnetic evaluation}

The electromagnetic characterization of nanostructured composites was carried out according to the transmission/ reflection method using a waveguide in the frequency range of 8.2 to $12.4 \mathrm{GHz}$ (X-band). These analyses aimed to calculate the reflection loss (reflectivity) and the electric permittivity $(\varepsilon)$ and the magnetic permeability $(\mu)$ as functions of the frequency. A Hewlett-Packard X752C waveguide (for X-band) with rectangular cross section was 
coupled to a system consisting of a vector network analyzer Agilent $8510 \mathrm{C}$, a frequency generator Hewlett-Packard 8340B (10 MHz-26.56 GHz) and an S-parameter test Hewlett-Packard 8510A (45 MHz-26.56 GHz). Adapters and coaxial cables for low loss applications Sucoform SM-141-Pe (50 ohms) were also used in the measurements (Agilent kit WR90). This setup measured the S-parameters ${ }^{51}$ of the material, i. e., the reflection $\left(\mathrm{S}_{11}\right)$ and transmission $\left(\mathrm{S}_{21}\right)$ coefficients to calculate $\varepsilon$ and $\mu$ as functions of the frequency. For this, a commercial software (Agilent 85071E) was used. To evaluate the reflectivity of the nanostructured formulations, an aluminum plate was used as reference, representing a material that reflects $100 \%$ of the incident radiation. To ensure electrical contact of the specimen with the waveguide, the liquid formulations were poured in a mold with exactly the same cross-section dimensions (length $22.9 \pm 0.01 \mathrm{~mm}$ and width $10.2 \pm 0.01 \mathrm{~mm}$ ) of the sample holder used in the electromagnetic measurements. The thickness of all specimens was $9.0 \mathrm{~mm}$.

\section{Results and Discussion}

\subsection{Scanning electron microscopy}

When dispersing conductive particles with diameters below $1 \mathrm{~mm}$ in a material of low viscosity, diffusion processes and particle-particle interaction forces play an important role in the agglomeration and network formation. Electrostatic charging of particles can both aid dispersion and hinder the aggregation required in order to achieve a network of touching particles. In certain circumstances, thermal energy alone is insufficient to surmount the potential energy barrier to aggregation and specific measures need to be taken. The application of low shear forces has already been shown to greatly enhance the migration of dispersed carbon nanotubes and the resulting network formation at loadings below $1.0 \%(\mathrm{w} / \mathrm{w})$ in an epoxy matrix ${ }^{55-58}$. These results indicate that the processing conditions play a crucial role in achieving low percolation thresholds in epoxy systems.

Figures 1 and 2 show the images obtained by SEM of the materials processed. It can be observed in Figure 1 that the nanotubes were poorly distributed and the presence of clusters in island $(0.1 \%$ (w/w) CNT/epoxy composite) in polymer matrix. However, within the island the CNTs are dispersed indicating that they form an interconnected network.

Figure 2 shows a more homogeneous dispersion. Correlating this result to that one observed in Figure 1 it is assumed that the relatively high volume fraction of CNTs $(0.5 \%(\mathrm{w} / \mathrm{w})$ promoted the presence a large number of agglomerates homogeneously distributed in the epoxy matrix. Only very few singly agglomerates are observed. Figure $2 \mathrm{~b}$ shows a similar morphology for higher CNT concentration $(1.0 \% \mathrm{w} / \mathrm{w})$ in the composite. A network structure formed by CNTs is clearly visible. This network is desired because it facilitates the transport of electrons through the material improving their electromagnetic properties.
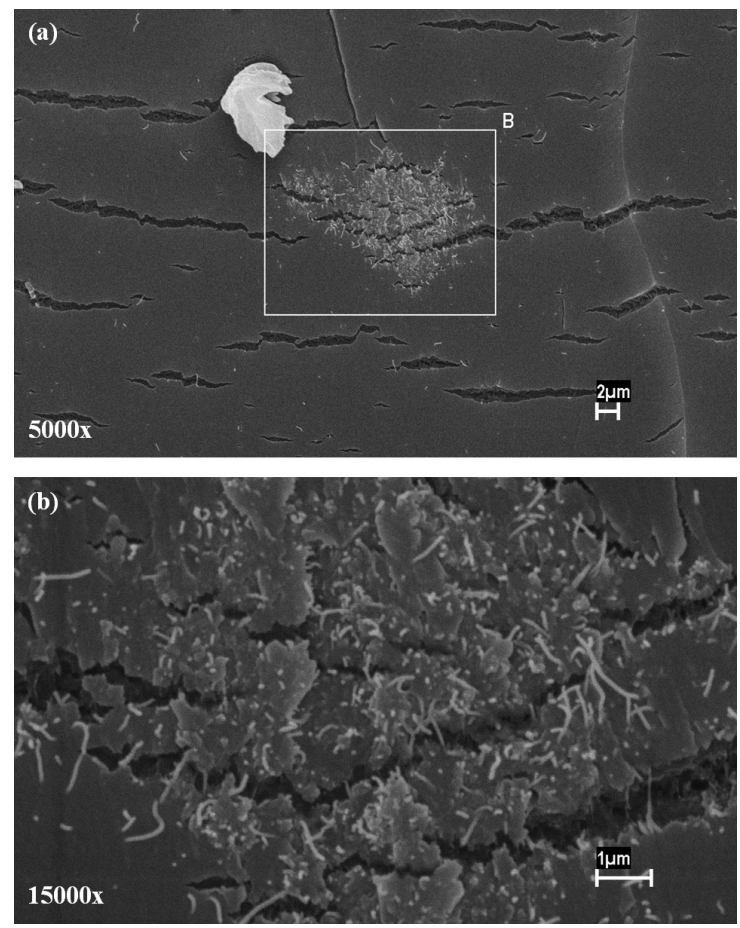

Figure 1. SEM of nanocomposite containing $0.1 \%$ (w/w) CNT: the network of dispersed CNTs is visible as white/black spots throughout the material (a) and island detail in the surface (b).
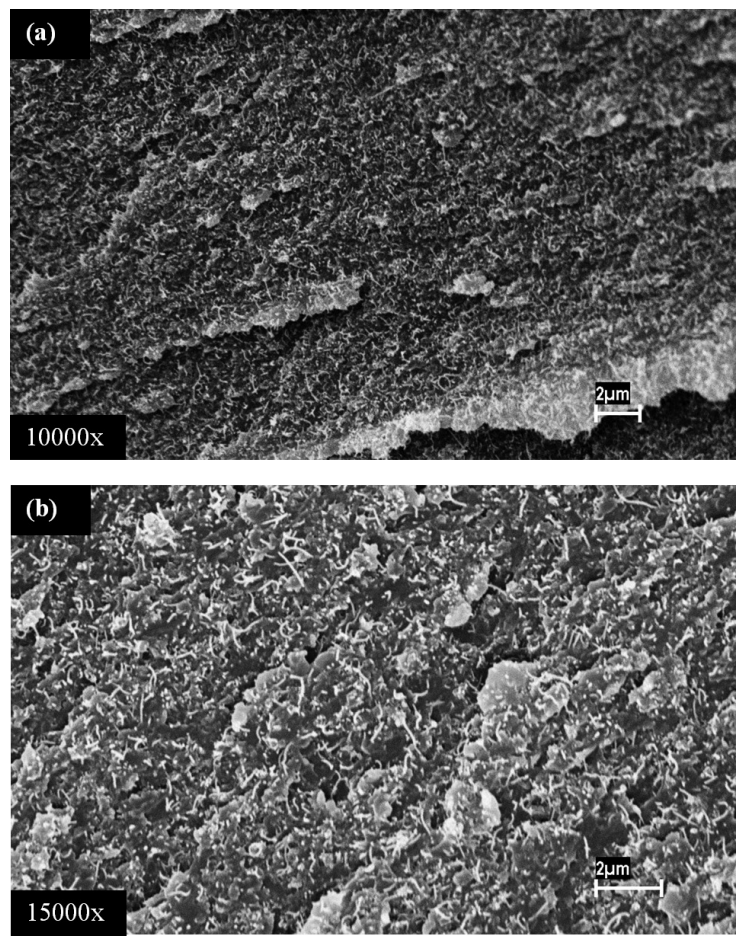

Figure 2. SEM of material containing $0.5 \%$ (w/w) (a) and $1.0 \%$ (w/w) (b), in which the network region formed by CNTs becomes easily visible. 


\subsection{Rheological properties}

Figures 3-5 show the viscoelastic behavior of formulations $0.1,0.5$ and $1.0 \%$ (w/w) CNT dispersed in epoxy matrix, respectively. Typical response curves used for linear viscoelastic study when is considered strain/ stress limit are obtained. These tests were performed only in order to evaluate the critical strain/stress limit of the linear viscoelastic state. According to these curves, for all formulations processed with $\mathrm{CNT}, 200 \mathrm{~Pa}$ as stress value can be used. In all plots, the neat epoxy resin showed a typical Newtonian behavior in which the relatively low viscosity (around 2 Pa.s) of the resin was independent of the frequency of the applied stress. On the other hand, the CNT reinforced composites exhibited a typical pseudo-plastic behavior.

In Figure 3 is depicted the complex viscosity $\left(\eta^{*}\right)$ as function of time for all formulations CNTs-epoxy mixtures. The plots show the drastic increase in the complex viscosity of the carbon nanotube/epoxy suspensions with increasing loading fractions. The initial complex viscosity of epoxy pure resin is $2 \mathrm{~Pa} . \mathrm{s}$; $0.1 \%$ (w/w) CNT-epoxy is $2.8 \mathrm{~Pa} . \mathrm{s}$;

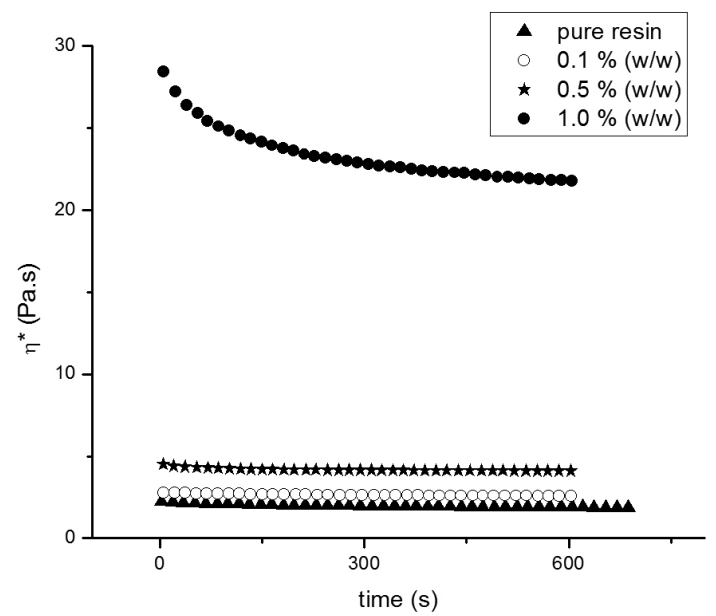

Figure 3. Complex viscosity as function time for all CNTs-epoxy mixtures.

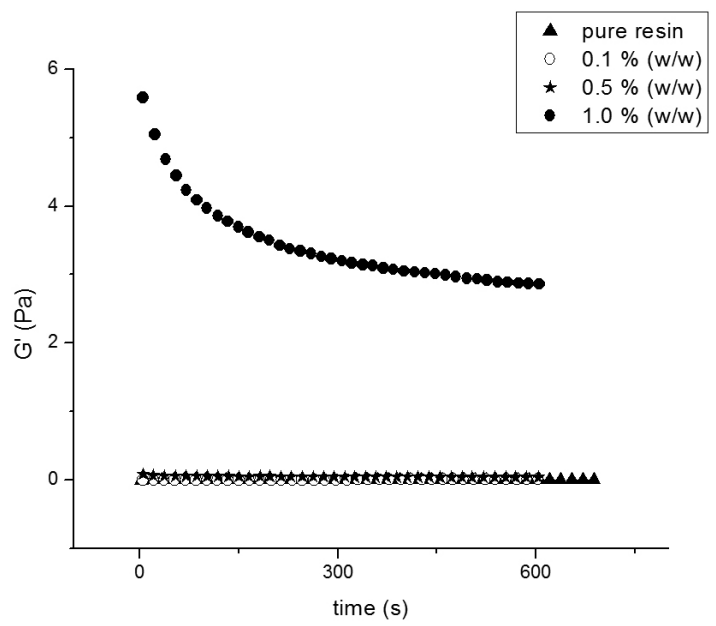

Figure 4. Elastic modulus $\left(\mathrm{G}^{\prime}\right)$ as function of time for all CNTsepoxy mixtures.
$0.5 \%(\mathrm{w} / \mathrm{w})$ is $4.5 \mathrm{~Pa}$.s and $1.0 \%(\mathrm{w} / \mathrm{w})$ is $28 \mathrm{~Pa}$.s. The addition of only $1.0 \%(\mathrm{w} / \mathrm{w}) \mathrm{CNT}$ in the epoxy resin system increase its viscosity more than 10 times. This behavior can be explained due to the fact of solid particles of high aspect ratio are been incorporated in the liquid system (epoxy matrix). This is one of the problems to produce nanomaterials with high filler content of CNTs. Higher loadings resulted in samples containing numerous voids, because air bubbles were trapped during the processing due to the high viscosity. However, it would be desirable to further increase the filler content of CNTs. If a good state of dispersion is reached, the mechanical properties should benefit from a higher loading fraction. Furthermore, the electrical conductivity of the nanocomposites also increases with increasing CNT content ${ }^{37}$.

Figure 4 shows the elastic modulus $\left(G^{\prime}\right)$ as function of time for all formulations CNT-epoxy mixtures. The increase of the elastic modulus with the increase of the loading carbon nanotubes content in the system suggests that the good dispersion was reached once the improvement on the mechanical property can be observed. The elastic modulus of epoxy pure resin increases of $0.0043 \mathrm{~Pa}$ to $3.2 \mathrm{~Pa}$ with addition of $1.0 \% \mathrm{w} / \mathrm{w}$ CNT in the system.

A plot of the frequency-dependent storage modulus is shown in Figure 5. In this case, the magnitude of G' increases with loading, accompanied by a flattening in the slope of response. This frequency-independent behavior at low $\omega$ (angular frequency) is indicative of increasing solid like elastic response. In addition, the distinct jump in the low-frequency magnitude of G' between 0.5 and $1.0 \%$ $(w / w)$ is an indicative of percolation behavior. In this case, the transition in behavior is evidenced by both an enhanced resistance to flow and increased degree of shear thinning.

\subsection{Dynamic mechanical analysis}

Dynamic mechanical analysis measurements were performed to find the storage modulus ( $\left.E^{\prime}\right)$, the loss modulus (E') and the glass transition temperature ( $\mathrm{Tg}$ ), and the results are summarized for neat epoxy resin (pure) and nanostructured composites CNT/epoxy in Table 1 and Figure 6.

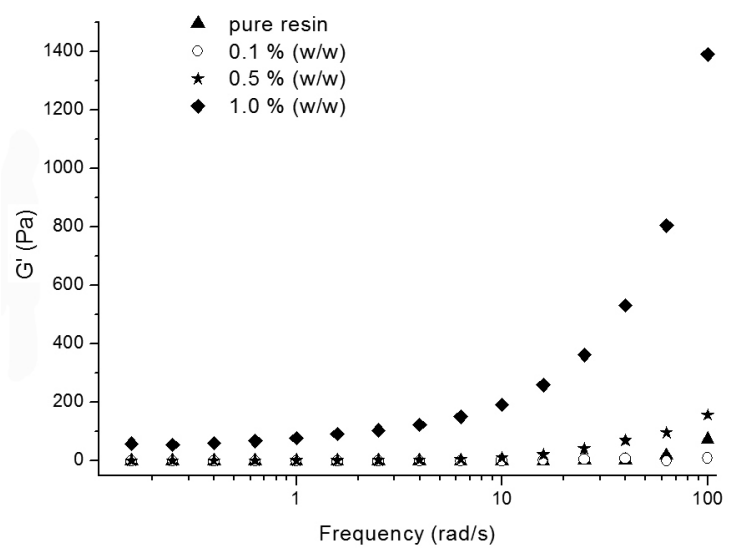

Figure 5. Storage modulus as function of frequency for all formulations of CNTs-epoxy mixtures. 


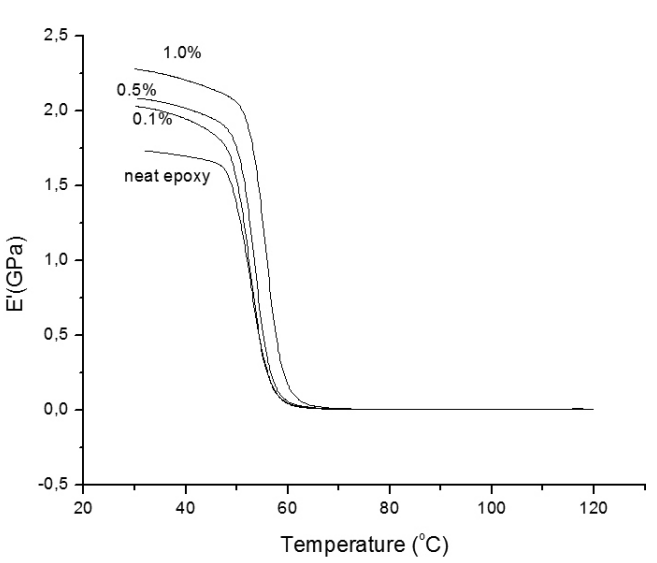

(a)

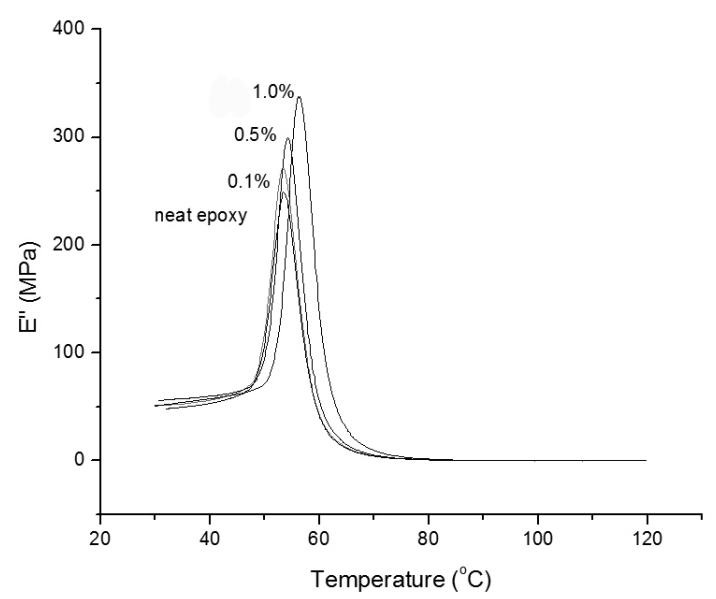

(b)

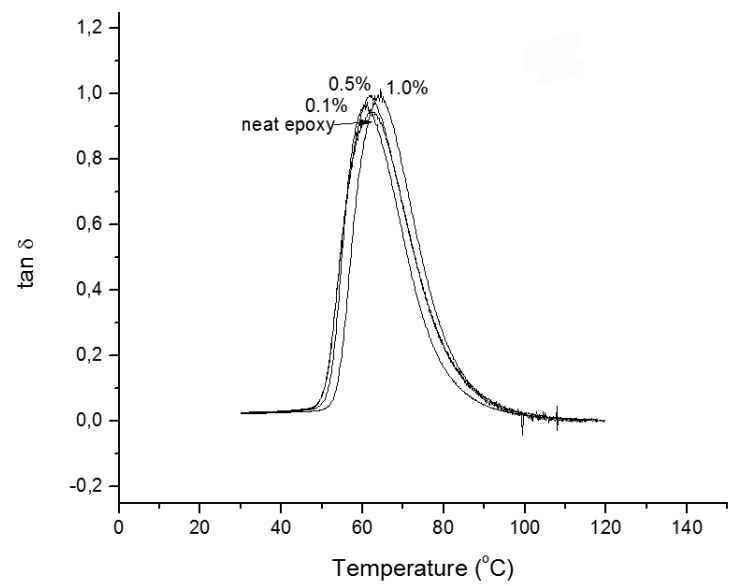

(c)

Figure 6. DMA results for nanostructured composites CNT/epoxy: (a) storage modulus (E'), (b) loss modulus (E”) and (c) tan $\delta$ as function of temperature.

Table 1. DMA measurements for nanostructured composites CNT/ epoxy (E' and E" reported at $\left.30^{\circ} \mathrm{C}\right)$.

\begin{tabular}{cccc}
\hline$\%(w / w)$ & $\mathbf{E}^{\prime}(\mathbf{G P a})$ & $\mathbf{E}{ }^{\prime}(\mathbf{M P a})$ & $\mathbf{T g}\left({ }^{\circ} \mathbf{C}\right) \mathbf{b y} \tan \delta$ \\
\hline Neat epoxy & $1.73 \pm 0.1$ & $48 \pm 7$ & $60.7 \pm 0.1$ \\
0.1 & $2.03 \pm 0.3$ & $51 \pm 9$ & $61.9 \pm 1.7$ \\
0.5 & $2.08 \pm 0.3$ & $56 \pm 8$ & $62.1 \pm 1.3$ \\
1.0 & $2.30 \pm 0.3$ & $51 \pm 9$ & $64.3 \pm 1.2$ \\
\hline
\end{tabular}

CNT has been reported to improve the mechanical properties of nanostructured composites ${ }^{16,37,42,43,59,60}$. However, the reported weight or volume fractions were much higher (50-100 times) than the ones used in this study. For such extremely low weight fractions of nanotubes used in our study, minimal change is expected in the mechanical properties. The storage modulus and loss modulus values are reported in Table 1 for measurements at $30^{\circ} \mathrm{C}$, whereas the modulus values during complete temperature scanning, starting from room temperature to well above glass transition, is shown in Figure 6. The effect of different weight fractions of CNT on the storage modulus, E' (Figure 6a) and the loss modulus, E" (Figure $6 b$ ) and the tan $\delta$ curves (glass transition temperatures, $\mathrm{Tg}$ is measured corresponding to the peak),
(Figure 6c) and comparison with neat epoxy is shown in Figure 6. The storage modulus has a slightly increase as compared with neat epoxy for nanostructured composites CNT/epoxy. The storage modulus for nanostructured composites CNT/epoxy seems to be slightly increased, especially for $1.0 \% \mathrm{w} / \mathrm{w}$ CNT. Probably, the addition of CNT in the epoxy system increases slightly the stiffness of the composites as compared with neat epoxy.

The loss modulus and the glass transition temperature measured from the DMA test can give some information about the dispersion state of the nanotubes throughout the specimen and the effect of localized dispersion state on the overall transition behavior from glassy to rubbery state. The changes in loss modulus are related to the changes in energy dissipation mechanisms, and the change in glass transition temperature is related to the mobility of polymeric chains during the transition from glassy to rubbery state ${ }^{16}$.

As seen from Figure $6 \mathrm{~b}$ and Table 1, the loss modulus for nanostructured composites CNT/epoxy is comparable to the neat epoxy modulus and lies within the standard deviation. The loss modulus values at room temperature for $0.5 \mathrm{wt} \% \mathrm{CNT}$ as the same as compared with the neat epoxy. The increase in loss modulus should be observed for all specimens due to the increased energy dissipation in the 
form of heat as a result of nanotube-nanotube friction. But this fact is not observed in our work. The slightly increase in $\mathrm{Tg}$ (about $4{ }^{\circ} \mathrm{C}$, almost insignificant) for such small weight fractions seems to be related to the localized dispersion state of nanotubes in epoxy matrix. Polymeric chains start moving during the transition process from glassy to rubbery state. The presence of nanotube bundles acts as a hurdle for movement of molecular chains of polymer at temperatures around the $\mathrm{Tg}$, which in turn leads to an increase in the glass transition temperature showed a slightly increase for nanostructured composites CNT/epoxy, as shown in Figure $6 \mathrm{c}$

\subsection{Thermogravimetry}

As shown in Figure 7, the introducing of CNT does not affect the initial decomposition temperature of the matrix. However, because the presence of the CNT in the composites the final profile of the TGA curve is different. In the neat epoxy curve it can be observed all polymeric matrix is degraded while in the nanostructured composites CNT/ epoxy curves a residue of CNT is observed.

According to Chen et al. ${ }^{61}$ if a good dispersion was obtained and an interfacial zone between the matrix and CNT was established probably the composites will be an improvement in their thermal stability. However, this effect was not observed in the present work.

\subsection{Electromagnetic properties}

Figure 8 shows the reflectivity curves related to the electromagnetic properties of the nanocomposites formed with the epoxy resin and carbon nanotubes evaluated by waveguide technique. The black line, located at $0 \mathrm{~dB}$ corresponds to the evaluation of the reference material (aluminum plate) which is used in the reflectivity measurements, being this $100 \%$ reflector. The neat polymer matrix (without CNTs) placed on the aluminum plate presents a similar behavior of the reference material. Thus, the curves related to the metal plate and the polymer matrix coincides, because the epoxy resin is transparent in the evaluated frequency range ( 8.2 to $12.4 \mathrm{GHz}$ ).

The measurements of processed materials show maximum attenuation value of $-25 \mathrm{~dB}$ at $11 \mathrm{GHz}$ and -10 $\mathrm{dB}$ at $9.5 \mathrm{GHz}$ (attenuation of 99.7 and $90.0 \%$, respectively)

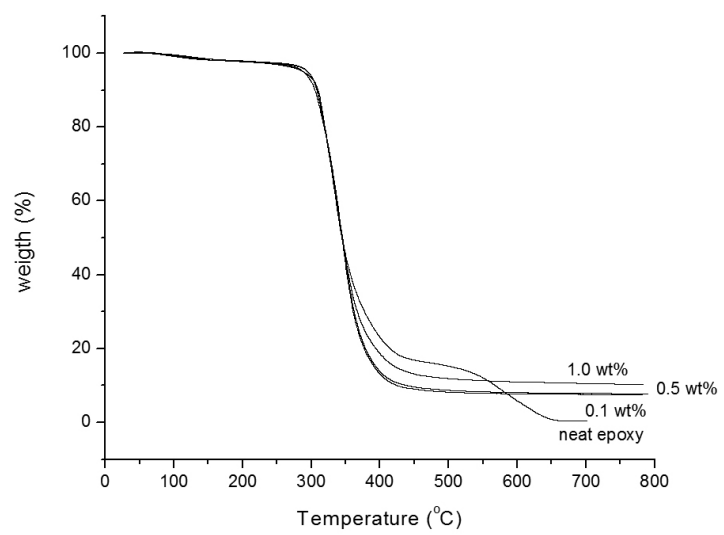

Figure 7. TGA curves of neat epoxy and nanostructured composites CNT/epoxy. for NCT formulations with 0.5 and $1.0 \%$ (w/w), respectively. These curves show that both CNT formulations promoted the impedance matching with the air favoring the wave propagation into the material and its attenuation ${ }^{62}$. SEM analyses (Figures 1 and 2) show the presence of NTC agglomerates after the dispersion in the resin. According to literature $^{63,64}$ these agglomerates act as electric conduction islands and favor the interaction of the electromagnetic wave with the material. It is also observed that the RAM samples evaluated behave as a narrow band absorber (resonance peak in the range of 9.5 and $11 \mathrm{GHz}$ ) in the evaluated frequency range ( 8.2 to $12.4 \mathrm{GHz}$ ).

The nanostructured composites with $0.1 \%$ (w/w) has a maximum of $-3 \mathrm{~dB}$ (at $12 \mathrm{GHz}$ ), corresponding to $50 \%$ of absorption of the incident wave. This sample does not perform well in the frequency range tested (8.2-12.4 GHz). These results show that different formulations lead to different behaviors, due to different impedance matching values $^{62}$, which may or not favor the radiation propagation into the material and its attenuation. Another factor that defined the obtained reflectivity curves and that might be taken into account is the thickness of the specimens ${ }^{62}$. Then, the obtained curves are typical for the studied nanostructured composite formulations considering the specimen thickness of $9.0 \mathrm{~mm}$. Any change in this parameter can shift the curves for different frequency values.

Figure 9 shows the behavior of the complex permittivity and permeability of the nanostructured composites absorbing materials as function of frequency. The measured values of the real and imaginary parts of the electrical permittivity were 3.5 and 0.3 (Figure 9a) for material with CNT $0.1 \%(w / w)$, respectively; for the other materials, with 0.5 and $1.0 \%(\mathrm{w} / \mathrm{w})$ the values are: 4.5 and 0.8 for the first formulation and 6.5 and 1.5, for the second (Figure 9c-b). The measured values of the real and imaginary parts of the magnetic permeability were 1.0 and 0.1 for all materials, as expected. As the processed materials are dielectric absorbers, the values of magnetic losses are so low that they can be disregarded $\left(\mu^{\prime}=1, \mu^{\prime \prime} \approx 0\right)$

For definition ${ }^{63,64}$, the real relative permittivity values ( $\varepsilon=\varepsilon$ ' $-\mathrm{j} \varepsilon ")$ are always higher than the unit. A material which presents value zero of dielectric loss it will have the values of the permittivity complex parameters $\varepsilon^{\prime}=1$ e $\varepsilon^{\prime \prime}=0$.

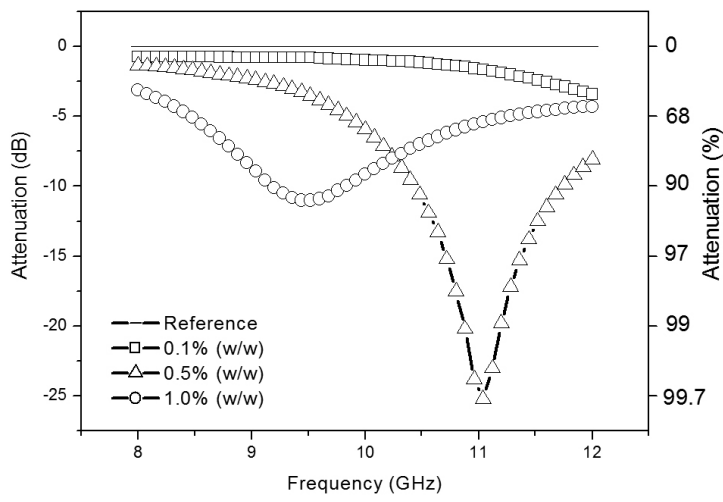

Figure 8. Attenuation of nanostructured composites processed with epoxy resin and different formulations of carbon nanotubes. 

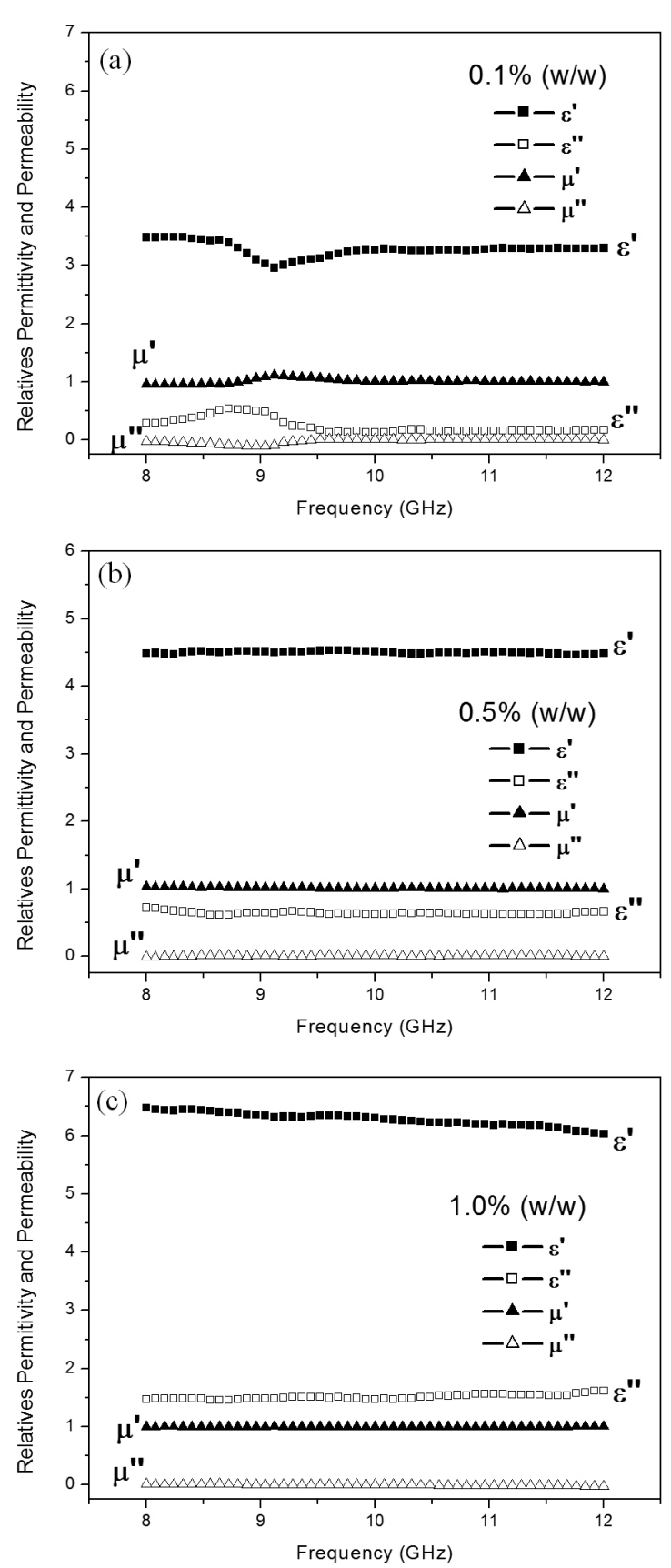

Figure 9. Real and imaginary permittivities ( $\varepsilon^{\prime}$ and $\varepsilon$ ") and permeabilities ( $\mu^{\prime}$ and $\left.\mu^{\prime \prime}\right)$ of the nanostructured composites, formulations with CNTs versus frequency: (a) $0.1 \%$ (w/w), (b) $0.5 \%(\mathrm{w} / \mathrm{w})$ and $(\mathrm{c}) 1.0 \%(\mathrm{w} / \mathrm{w})$.

So, it does not store energy $\left(\varepsilon^{\prime}=1\right)$ and, consequently, it does not present losses $(\varepsilon "=0)$. Thus, the higher the imaginary component is ( $\left.\varepsilon^{\prime \prime}\right)$, the higher the capacity of material loss will be. A material with low dielectric loss can store energy, but it will not dissipate a lot of the energy stored. On the other hand, a material with high value of dielectric loss, does not actually store energy, but a certain amount of the stored energy will be converted into thermal energy inside the material, that is, the material attenuates the electromagnetic energy instead of just storing it.
The permittivity of material with CNT $0.5 \%$ (w/w) has lower dielectric loss compared to material with $1.0 \%$ (w/w). This behavior is characteristic of dielectric materials with low electric conductivity. On the other hand, the material with $1.0 \%(\mathrm{w} / \mathrm{w})$ has intrinsic attenuation of incident wave, i. e., an adequate electrical conductivity versus concentration of formulation; probably it reached the percolating limit of material. These results allow concluding that the maximum attenuation observed in Figure 8 for the sample with $0.5 \%(\mathrm{w} / \mathrm{w})$ has a significant contribution of the wave phase cancelling thanks the adequate correlation among the impedance match, the used sample thickness and the evaluated frequency range.

\section{Conclusions}

A processing method was developed for preparing nanostructured composites containing varying weight fractions CNTs/epoxy resin, whose physical, chemical and electromagnetic properties are investigated in this work. The results are presented with respect to the variation of the microstructure as observed from scanning electron microscopy technique in which can be observed the presence of agglomerates of carbon nanotubes in the epoxy matrix. From the rheological analyses, it was observed the initial complex viscosity is increased with the nanotube contents increase. The elastic modulus, loss modulus, $\mathrm{Tg}$ and decomposition temperature are practically do not affected with the introduction of carbon nanotubes in the epoxy matrix.

The distinct behaviors of electromagnetic radiation attenuation of the processed materials suggest that the electric conduction characteristic is related to the amount of absorbing center present in these; changing the impedance of the absorber and defining, as a consequence, the attenuation behavior of the incident radiation. Thus, for the absorbing materials, most of the electromagnetic energy must be attenuated; and for that there must be a balance between the electric conductivity and the dielectric loss factor.

The correlation of the results obtained leads to the conclusion that the distribution of carbon nanotubes agglomerates in the epoxy resin favored the impedance matching of the prepared nanostructured composite. Based on the results obtained in this study, we conclude that the nanostructured composites CNT/epoxy produced have a good potential to be used as RAM, since they absorbed 50 to $99.7 \%$ of the incident electromagnetic radiation, using only $0.5 \%$ (w/w) of CNT. The attenuation measured for the absorbing nanostructured composites containing carbon nanotubes can be explained by the fact that when this center absorbing is surrounded by a matrix, conduction paths are formed in the material, allowing the dissipation of energy due to electrical losses.

\section{Acknowledgements}

The authors wish to thank the Departamento de Ciência e Tecnologia Aeroespacial (DCTA) for the technical support and the Brazilian government funding agency $\mathrm{CNPq}$ (Project numbers: 305478/2009-5, 559246/2008-0, 151803/2008-0 and 151154/2009-0) for the financial support. 


\section{References}

1. Deng L and Han M. Microwave absorbing performances of multiwalled carbon nanotube composites with negative permeability. Applied Physical Letter. 2007; 9(1):2311923121. http://dx.doi.org/10.1063/1.2755875

2. Lin $\mathrm{H}, \mathrm{Zhu} \mathrm{H}$ and Guo LY. Materials processing by simple shear. Materials Letter. 2007; 61(2):3547-3550. http://dx.doi. org/10.1016/j.matlet.2007.01.077

3. Folgueras LC, Nohara EL, Faez R and Rezende MC. Dielectric microwave absorbing material processed by impregnation of carbon fiber fabric with polyaniline. Materials Research. 2007; 10(1):95-99. http://dx.doi.org/10.1590/S151614392007000100020

4. Seo IS, Chin WS and Lee DG. Characterization of electromagnetic properties of polymeric composite materials with free space method. Composite Structures. 2004; 66:533542. http://dx.doi.org/10.1016/j.compstruct.2004.04.076

5. Kim YJ and Kim SS. Microwave absorbing properties of Cosubstituted $\mathrm{Ni}_{2} \mathrm{~W}$ hexaferrites in Ka-band frequencies (26.5-40 GHz). IEEE Transaction on Magnetics. 2002; 38:3108-3110. http://dx.doi.org/10.1109/TMAG.2002.802483

6. Horvath MP. Microwave applications of soft ferrites. Journal Magnetism and Magnetic Materials. 2000; 215-216:171-183. http://dx.doi.org/10.1016/S0304-8853(00)00106-2

7. Petrov VM and Gagulin VV. Microwave Absorbing Materials Inorganic Materials. 2001; 37(2):93-98. http://dx.doi. org/10.1023/A:1004171120638

8. Folgueras LC, Alves MA and Rezende MC. Electromagnetic radiation absorbing paints based on carbonyl iron and polyaniline. In: Proceedings of the Internacional Microwave and Optoeletronics Conference; 2009. IEEE; 2009. v. 1, p. 510-513. http://dx.doi.org/10.1109/imoc.2009.5427534

9. Emerson WL. Electromagnetic wave absorbers and anechoic chambers through the years. IEEE Transactions on Antennas and Propagation. 1973; 21:484-490. http://dx.doi.org/10.1109/ TAP.1973.1140517

10. Kazantseva NE, Saha N, Sedlarik V, Saha P and Kar S Magnetic materials based on manganese-zinc ferrite with surface-organized polyaniline coating. Journal of Magnetism and Magnetic Materials. 2006; 301(1):155-165. http://dx.doi. org/10.1016/j.jmmm.2005.06.015

11. Gupta SC, Agrawal NK and Kumar C. Design of a single layer broadband microwave absorber using cobalt-substituted barium hexagonal ferrite. In: IEEE-MTTS: International Microwave Symposium Digest; 1992. IEEE; 1992. v. 1, p. 317-320. http:// xplqa30.ieee.org/stamp/stamp.jsp?tp=\&arnumber $=187976$.

12. Dishovski N, Petkov A, Nedkob I and Razkazov I. Hexaferrite contribution to microwave absorbers characteristics. IEEE Transaction on Magnetics. 1994; 30:969-971. http://dx.doi. org/10.1109/20.312461

13. Lee SM. International Encyclopedia of Composites. New York: VHC Publishers; 1991.

14. Yusoff AN and Abdullah MH. Microwave electromagnetic and absorption properties of some LiZn ferrites. Journal of Magnetism and Magnetic Materials. 2004; 269:271-280. http:// dx.doi.org/10.1016/S0304-8853(03)00617-6

15. Hongfeng X, Binghua L, Yuan Z, Shen J and Cheng RJ. Cure kinetics of carbon nanotube/tetrafunctional epoxy nanocomposites by isothermal differential scanning calorimetry. Polymer Science: Part B: Polymer Physics. 2004; 42:37013712. http://dx.doi.org/10.1002/polb.20220

16. Jia W, Tchoudakov R, Joseph R, Narkis M and Siegmann A. The conductivity behavior of multi-component epoxy, metal particle, carbon black, carbon fibril composites. Journal Applied Polymer Science. 2002; 85:1706-1713. http://dx.doi. org/10.1002/app.10808

17. Mijovic J and Wang HT. Cure kinetics of neat and graphitefiber-reinforced epoxy formulations. Journal Applied Polymer Science. 1989; 37:2661-2673. http://dx.doi.org/10.1002/ app.1989.070370917

18. Kawaguchi T and Pearson RA. The effect of particle-matrix adhesion on the mechanical behavior of glass filled epoxies: Part 1. A study on yield behavior and cohesive strength. Polymer. 2003; 44:4229-4238. http://dx.doi.org/10.1016/ S0032-3861(03)00371-9

19. Gong X, Liu J, Baskaran S, Voise RD and Young JS. SurfactantAssisted Processing of Carbon Nanotube/Polymer Composites. Chemistry of Materials. 2000; 12:1049-1052. http://dx.doi. org/10.1021/cm9906396

20. Goh HW, Goh SH, Xu GQ, Pramoda KP and Zhang WD. Dynamic mechanical behavior of in situ functionalized multiwalled carbon nanotube/phenoxy resin composite. Chemical Physics Letters. 2003; 373:277-283. http://dx.doi.org/10.1016/ S0009-2614(03)00621-3

21. XuX,Thwe MM,Shearwood CandLiao K. Mechanical properties and interfacial characteristics of carbon-nanotube-reinforced epoxy thin films. Applied Physics Letters. 2002; 81:2833-2835. http://dx.doi.org/10.1063/1.1511532

22. Lau KT and Shi SQ. Failure mechanisms of carbon nanotube/ epoxy composites pretreated in different temperature environments. Carbon. 2002; 40:2965-2968. http://dx.doi. org/10.1016/S0008-6223(02)00245-2

23. Sandler J, Shaffer MSP, Prasse T, Bauhofer W, Schulte K and Windle AH. Development of a dispersion process for carbon nanotubes in an epoxy matrix and the resulting electrical properties. Polymer. 1999; 40:5967-5971. http://dx.doi. org/10.1016/S0032-3861(99)00166-4

24. Hone J, Llaguno MC, Biercuk MJ, Johnson AT, Batlogg B, Benes $\mathrm{Z}$ et al. Thermal properties of carbon nanotubes and nanotube-based materials. Applied Physics A. 2002; 74:339343. http://dx.doi.org/10.1007/s003390201277

25. Biercuk MJ, Llaguno MC, Radosavljevic M, Hyun JK and Johnson AT. Carbon nanotube composites for thermal management. Applied Physics Letters. 2002; 80:2767-2769. http://dx.doi.org/10.1063/1.1469696

26. Spitalsky Z, Tasis D, Papagelis K and Galiotis C. Carbon nanotube-polymer composites: Chemistry, processing, mechanical and electrical properties. Progress in Polymer Science. 2010; 35:357-401. http://dx.doi.org/10.1016/j. progpolymsci.2009.09.003

27. Thakre PR, Bisrat $Y$ and Lagoudas DC. Electrical and mechanical properties of carbon nanotube-epoxy nanocomposites. Journal Applied Polymer Science. 2010; 116:191-202. http://dx.doi. org/10.1002/app.31122

28. Bal S. Influence of dispersion states of carbon nanotubes on mechanical and electrical properties of epoxy nanocomposites. Journal of Scientific \& Industrial Research. 2007; 66(9):752-756.

29. Chen H, Muthuraman H, Stokes P, Zou JH, Liu X, Wang $\mathrm{JH}$ et al. Dispersion of carbon nanotubes and polymer nanocomposite fabrication using trifluoroacetic acid as a cosolvent. Nanotechnology. 2007; 18:415606/1-415606/9. http:// dx.doi.org/10.1088/0957-4484/18/41/415606

30. Grossiord N, Loos J, Regev O and Koning CE. Toolbox for Dispersing Carbon Nanotubes into Polymers To Get Conductive Nanocomposites. Chemistry of Materials. 2006; 18:1089-1099. http://dx.doi.org/10.1021/cm051881h 
31. Liu L and Grunlan JC. Clay Assisted Dispersion of Carbon Nanotubes in Conductive Epoxy Nanocomposites. Advanced Functional Materials. 2007; 17:2343-2348. http://dx.doi. org/10.1002/adfm.200600785

32. Gojny FH, Wichmann MHG, Fiedler B, Kinloch IA, Bauhofer $\mathrm{W}$, Windle $\mathrm{AH}$ et al. Evaluation and identification of electrical and thermal conduction mechanisms in carbon nanotube/ epoxy composites. Polymer. 2006; 47:2036-2045. http://dx.doi. org/10.1016/j.polymer.2006.01.029

33. Schmidt RH, Kinloch IA, Burgess AN and Windle AH. The Effect of Aggregation on the Electrical Conductivity of Spin-Coated Polymer/Carbon Nanotube Composite Films. Langmuir. 2007; 23:5707- 5712. PMid:17417882. http://dx.doi. org/10.1021/la062794m

34. Bai JB and Allaoui A. Effect of the length and the aggregate size of MWNTs on the improvement efficiency of the mechanical and electrical properties of nanocomposites-experimental investigation. Composites: Part A. 2003; 34:689-694. http:// dx.doi.org/10.1016/S1359-835X(03)00140-4

35. Li J, Ma PC, Chow W, To CK and Tang BZ, Kim JK. Correlations between Percolation Threshold, Dispersion State, and Aspect Ratio of Carbon Nanotubes. Advanced Functional Materials. 2007; 17:3207-3215. http://dx.doi.org/10.1002/ adfm. 200700065

36. Martin CA, Sandler JKW, Shaffer MSP, Schwarz MK, Bauhofer $\mathrm{W}$, Schulte $\mathrm{K}$ et al. Formation of percolating networks in multiwall carbon-nanotube-epoxy composites. Composite Science Technology. 2004; 64:2309-2316. http://dx.doi.org/10.1016/j. compscitech.2004.01.025

37. Wichmann MHG, Sumfleth J, Fiedler B, Gojny FH and Schulte K. Multiwall carbon nanotube/epoxy composites produced by a masterbatch process. Mechanics of Composite Materials. 2006; 42:395-406. http://dx.doi.org/10.1007/ s11029-006-0050-3

38. Lau KT, Lu M and Liao K. Improved mechanical properties of coiled carbon nanotubes reinforced epoxy nanocomposites. Composites Applied Science Manufacturing. 2006; 37:18371840. http://dx.doi.org/10.1016/j.compositesa.2005.09.019

39. Lanticse LJ, Tanabe Y, Matsui K, Kaburagi Y, Suda K, Hoteida $\mathrm{M}$ et al. Shear-induced preferential alignment of carbon nanotubes resulted in anisotropic electrical conductivity of polymer composites. Carbon. 2006; 44:3078-3086. http:// dx.doi.org/10.1016/j.carbon.2006.05.008

40. Pecastaings G, Delhaes P, Derre A, Saadaoui H, Carmona F and Cui S. Role of Interfacial Effects in Carbon Nanotube/ Epoxy Nanocomposite Behavior. Journal of Nanoscience and Nanotechnology. 2004; 4:838-843. PMid:15570969. http:// dx.doi.org/10.1166/jnn.2004.114

41. Mitchell CA, Bahr JL, Arepalli S, Tour JM and Krishnamoorti R. Dispersion of Functionalized Carbon Nanotubes in Polystyrene. Macromolecules. 2002; 35:8825-8830. http:// dx.doi.org/10.1021/ma020890y

42. Zhu J, Kim JD, Peng HQ, Margrave JL, Khabashesku V and Barrera EV. Improving the Dispersion and Integration of Single-Walled Carbon Nanotubes in Epoxy Composites through Functionalization. Nano Letters. 2003; 3:1107-1113. http://dx.doi.org/10.1021/n10342489

43. Zhu J, Peng HQ, Rodriguez M, Margrave JL, Khabasheskhu VN, Imam AM et al. Reinforcing Epoxy Polymer Composites Through Covalent Integration of Functionalized Nanotubes. Advanced Functional Materials. 2004; 14:643-648. http:// dx.doi.org/10.1002/adfm.200305162

44. Santos AS, Leite TDN, Furtado CA, Welter C, Pardini LC and Silva GG. Morphology, thermal expansion, and electrical conductivity of multiwalled carbon nanotube/epoxy composites. Journal Applied Polymer Science. 2008; 108:979986. http://dx.doi.org/10.1002/app.27614

45. Zilli D, Goyanes S, Escobar MM, Chiliotte C, Bekeris $\mathrm{V}$, Cukierman AL et al. Comparative analysis of electric, magnetic, and mechanical properties of epoxy matrix composites with different contents of multiple walled carbon nanotubes. Polymer Composites. 2007; 28:612-617. http:// dx.doi.org/10.1002/pc.20288

46. Thostenson ET and Chou TW. Processing-structure-multifunctional property relationship in carbon nanotube/epoxy composites. Carbon. 2006; 44:3022-3029. http://dx.doi. org/10.1016/j.carbon.2006.05.014

47. Moniruzzaman M and Winey KI. Polymer Nanocomposites Containing Carbon Nanotubes. Macromolecules. 2006; 39:51945205. http://dx.doi.org/10.1021/ma060733p

48. Dragoman M, Takacs A, Muller AA, Hartnagel H, Plana R, Grenier $\mathrm{K}$ et al. Experimental determination of microwave attenuation and electrical permittivity of double-walled carbon nanotubes. Applied Physics Letters. 2006; 88:153108153108/3. http://dx.doi.org/10.1063/1.2193464

49. Liu Z, Bai G, Huang Y, Li F, Ma Y, Guo T et al. Microwave Absorption of Single-Walled Carbon Nanotubes/Soluble Cross-Linked Polyurethane Composites. Journal of Physical Chemistry C. 2007; 111:13696-13700. http://dx.doi. org/10.1021/jp0731396

50. Kim JB, Lee SK and Kim CG. Comparison study on the effect of carbon nano materials for single-layer microwave absorbers in X-band. Composites Science and Technology. 2008; 68:29092916. http://dx.doi.org/10.1016/j.compscitech.2007.10.035

51. Micheli D, Pastore R, Gradoni G, Primiani VM, Moglie F and Marchetti M. Reduction of satellite electromagnetic scattering by carbon nanostructured multilayers. Acta Astronautica. 2013; 88:61-73. http://dx.doi.org/10.1016/j. actaastro.2013.03.003

52. Micheli D, Apollo C, Pastore R, Barbera D, Morles RB, Marchetti M et al. Optimization of Multilayer Shields Made of Composite Nanostructured Materials. IEEE Electromagnetic Compatibility Society. 2012; 54:60-69. http://dx.doi. org/10.1109/TEMC.2011.2171688

53. Micheli D, Pastore R, Apollo C, Marchetti M, Gradoni G, Primiani VM and Moglie F. Broadband Electromagnetic Absorbers Using Carbon Nanostructure-Based Composites. IEEE Transaction on Microwave Theory Techniques. 2011; 59:2633-2646. http://dx.doi.org/10.1109/ TMTT.2011.2160198

54. Micheli D, Apollo C, Pastore R and Marchetti M. X-Band microwave characterization of carbon-based nanocomposite material, absorption capability comparison and RAS design simulation. Composites Science and Technology. 2010; 70:400409. http://dx.doi.org/10.1016/j.compscitech.2009.11.015

55. American Society For Testing And Materials - ASTM. D5568-08: Standard Test Method for Measuring Relative Complex Permittivity and Relative Magnetic Permeability of Solid Materials at Microwave Frequencies Using Waveguide. ASTM; 2008.

56. Schueler R, Petermann J, Schulte K and Wentzel HP. Percolation in carbon black filled epoxy resin. Macromolecule Symposium. 1996; 104:261-268. http://dx.doi.org/10.1002/ masy. 19961040122

57. Schueler R, Petermann J, Schulte K and Wentzel HP. Agglomeration and electrical percolation behavior of carbon black dispersed in epoxy resin. Journal Applied Polymer Science. 1997; 63:1741-1746. http://dx.doi. 
org/10.1002/(SICI)1097-4628(19970328)63:13<1741::AIDAPP5 $>3.0 . C O ; 2-G$

58. Li L, Li CY, Ni C, Rong L and Hsiao B. Structure and crystallization behavior of Nylon 66/multi-walled carbon nanotube nanocomposites at low carbon nanotube contents. Polymer. 2007; 48:3452-3460. http://dx.doi.org/10.1016/j. polymer.2007.04.030

59. Bekyarova E, Thostenson ET, Yu A, Itkis ME, Fakhrutdinov D, Chou $\mathrm{T}$ et al. Functionalized Single-Walled Carbon Nanotubes for Carbon Fiber-Epoxy Composites. Journal of Physical Chemistry C. 2007; 111:17865-17871. http://dx.doi. org/10.1021/jp071329a

60. Miyagawa H, Misra M and Mohanty AK. Mechanical Properties of Carbon Nanotubes and Their Polymer Nanocomposites. Journal of Nanoscience \& Nanotechnology. 2005; 5:15931615. PMid:16245518. http://dx.doi.org/10.1166/jnn.2005.181
61. Chen GX, Kim HS, Park BH and Yoon JS. Multiwalled carbon nanotubes reinforced nylon 6 composites. Polymer. 2006; 47:4760-4767. http://dx.doi.org/10.1016/j. polymer.2006.04.020

62. Balanis CA. Antenna Theory: analysis and design. New York: John Wiley Sons; 1989.

63. Folgueras LC, Alves MA and Rezende MC. Microwave absorbing paints and sheets based on carbonyl iron and polyaniline: measurement and simulation of their properties. Journal of Aerospace Technology and Managment. 2010; 2:6370. http://dx.doi.org/10.5028/jatm.2010.02016370

64. Folgueras LC and Rezende MC. Multilayer radar absorbing material processing by using polymeric nonwoven and conducting polymer. Materials Research. 2008; 11:245-249. http://dx.doi.org/10.1590/S1516-14392008000300003 